\title{
Awareness regarding Janani Shishu Suraksha Karyakram among pregnant women of Marathwada, Maharashtra, India
}

\author{
Sonali Deshpande ${ }^{1 *}$, Shrinivas Gadappa ${ }^{1}$, Sanjaykumar Pagare $^{1}$, Rashmi Dhaduti ${ }^{1}$, \\ Smita Andurkar ${ }^{2}$
}

\author{
${ }^{1}$ Department of Obstetrics and Gynecology, Government Medical College, Aurangabad, Maharashtra, India \\ ${ }^{2}$ Department of Preventive and Social Medicine, Government Medical College, Latur, Maharashtra, India
}

Received: 21 April 2016

Accepted: 16 May 2016

*Correspondence:

Dr. Sonali Deshpande,

E-mail: sonalisd97@yahoo.co.in

Copyright: ( ) the author(s), publisher and licensee Medip Academy. This is an open-access article distributed under the terms of the Creative Commons Attribution Non-Commercial License, which permits unrestricted non-commercial use, distribution, and reproduction in any medium, provided the original work is properly cited.

\section{ABSTRACT}

Background: Government of India has launched “Janani Shishu Suraksha Karyakram” on 1st July 2011, to assure free and cashless services (including free transport) to all pregnant women and sick neonates accessing public health institutions. The objective of the study was to find out level of awareness regarding JSSK entitlement in pregnant women and to examine the association between different socio-demographic factors and awareness level.

Methods: This was a cross sectional study was conducted in the Department of Obstetrics and Gynaecology. Govt. Medical College and Hospital, Aurangabad involving 1000 pregnant women attending antenatal clinic between September 2015 to March 2016. Questionnaire was given to assess the awareness about JSSK entitlements and if it was known to them, then the source of information was noted. Information regarding socio-demographic characteristics was noted. The study subject was considered as aware of the scheme, if she had heard about the scheme and had knowledge about certain key points of the scheme. One point each was given to all the correctly answered questions and mean was calculated. Subjects whose correctly answered questions were more than the mean value were considered to have good awareness level. Analysis was done using SPSS version 20. Chi-square test for association between awareness level and different socio-demographic factors. Significance level was considered at $\mathrm{p}$ value $<0.05$.

Results: Among 1000 antenatal women, good awareness level regarding JSSK entitlements was seen in only 472 (47.2\%) study subjects. Maximum awareness regarding JSSK entitlements was noted to be for Free vaginal delivery in $869(86.90 \%)$ followed by free drugs and consumables to mother $(73.4 \%)$ and free treatment for sick infants 662 $(66.2 \%)$ and least awareness was noted for free drop back of sick infant from health facility to home (9\%) and free caesarean section (9.6\%). Not even a single woman answered all the 17 entitlements correctly. Only 13 (1.3\%) women were able to answer 16 questions correctly. Advancing age, increasing level of education, member of nuclear family, increasing number of conception (gravidity) and advanced gestational age are significantly associated with the level of awareness. However, religion, socioeconomic status and occupation did not have any statistical significant association with the level of awareness regarding various entitlements of JSSK in antenatal women. Regarding the source of information, the most common source of information was from health personnel, followed by friends and family. None of the women reported that Radio, TV, Newspaper had contributed as a source of information.

Conclusions: Awareness level of JSSK entitlements in the pregnant women in our study is low. Maximum awareness was noticed for the provision of free vaginal delivery whereas awareness for provisions like free caesarean section, free drop back facility to home, free provision of blood is very low. Further efforts are needed to increase the overall awareness of various entitlements of JSSK among pregnant women to increase the utilization of the benefits of the scheme and thus indirectly helping in reducing MMR and IMR.

Keywords: Awareness, Free transport service, JSSK entitlements, Free caesarean delivery 


\section{INTRODUCTION}

Maternal and child health is one of the eight Millennium Development Goals. Maternal and child mortality can be reduced by promoting institutional deliveries. Maternal Mortality Ratio and Infant Mortality Rate strongly reflect the overall effectiveness of health systems. ${ }^{1}$ India has MMR of 167/1, 00,000 and IMR of 40/1000 live births. Maharashtra being the 3rd largest state in India has MMR of 68 and IMR of $24 .^{2}$

Several initiatives have been launched by Ministry of Health and Welfare including Janani Suraksha Yojana (JSY) which is one of the key interventions that has resulted in phenomenal growth in institutional deliveries. However during programme review the state \& district programme officers highlighted the situation where at times there is paucity of essential logistics like drugs, consumables, facilities of referral etc. Such situations are often being exploited by unwarranted persons and the beneficiaries are subjected for incurring out of pocket expenses. Thus in order to reduce out of pocket expenses under the overall umbrella of NRHM, Janani Shishu Suraksha Karyakram was launched on 1st June 2011 ensuring free entitlements like cashless delivery, Csection and management of sick neonate up to 30 days. ${ }^{3}$

Marathwada region from Maharashtra is economically backward.The utilisation of any scheme depends on the level of awareness among beneficiaries. Despite of wide availability of the scheme, there is poor utilization of the JSSK entitlements either due to ignorance or due to incomplete erroneous information about their use and procurement. Awareness has been highlighted by many as a key indicator of success in a range of performance. Awareness level among beneficiaries helps us to know the extent to which the programme is serving the purpose at root level. It is important to generate region based evidence on the awareness of JSSK entitlements. There are very few studies regarding assessment of awareness of JSSK entitlements and there was not a single study from Marathwada region. Keeping this in mind, this study was conducted to know the level of awareness about various entitlements of JSSK among pregnant women and to examine the association between different socio-demographic factors and awareness level.

\section{METHODS}

The present cross sectional study was conducted in the Department of Obstetrics and Gynaecology, Govt. Medical College and Hospital, Aurangabad. Sample size was calculated using the formula $\mathrm{n}=4 \mathrm{pq} / \mathrm{L}^{2}(\mathrm{p}=$ positive character in \%, q=100-p, L=allowable error $10 \%$ of $\mathrm{p} . \mathrm{n}$ which was calculated was 880 and the sample size of our study is $n=1000$. $^{4}$

All antenatal cases who reported for registration from $1^{\text {st }}$ September 2015 onwards were given the option of being included in the study. Those who were not willing were not enrolled for the study group and unwilling cases were not required to give reason for reluctance. Informed consent was obtained from all respondents prior to participating in the study. Confidentiality was maintained in data collection and compilation. This study was terminated in March 2016 when the requisite sample size of 1000 cases in the study group was achieved. Both willing and unwilling cases went through routine and standard antenatal care. Age, parity and other sociodemographic parameters were noted. Those who were included in the study were given the questionnaire in the first visit only. Questionnaire included a part to know about the JSSK entitlements and if it was known to them, then the source of information was noted. Questionnaire included all JSSK entitlements like Free Normal Vaginal Delivery, Free Caesarean Section, Free treatment for sick infant, Free drugs and consumables for mother, Free drugs and consumables for sick infants, Free diagnostics for pregnant women, Free diagnostics for sick infant, Free diet for mother, Free provision of blood for mother, Free provision of blood for sick infant. Exemption from user charges for mother and sick infant, Free transport for mother from home to health facility, Free transport for mother between health facility, Free drop back from health facility to home after delivery, Free transport for sick infant from home to health facility, Free referral transport for sick infant between health facilities, Free drop back of sick infant from health facility to home. Data was collected using a predesigned and pretested data collection form.

The study subject was considered to be aware of the scheme if she had heard about the scheme and had knowledge about certain key points of the scheme. One point each was given to all the correctly answered questions and mean was calculated. Subjects whose correctly answered questions were more than the mean value were considered to have good awareness level. Analysis was done using SPSS version 20. Chi-square test was applied for association between awareness level and different socio-demographic factors. Significance level was considered at $\mathrm{p}$ value $<0.05$.

\section{RESULTS}

Table 1 showing socio-demographic profile of study participants revealed that maximum $(63.10 \%)$ women belonged to the age group of 20-24 years. There were $61.80 \%$ Hindu women. Around $96.2 \%$ were literate, out of which $70.30 \%$ women were educated up to middle and high school level. Around $85.7 \%$ were home-makers, $61.40 \%$ belonging to socioeconomic class 4 and $61.4 \%$ women were belonging to joint family. Majority $(53.30 \%)$ women were primigravida and $51.8 \%$ women were having Gestational age more than 20 weeks.

Table 2 showing statistical variables of correctly answered questions to assess awareness and the mean was found to be 6.22 , mode was 5 and range was between $0-16$. 
Table 1: Socio-demographic characteristics of study group.

\begin{tabular}{|c|c|c|c|}
\hline \multicolumn{2}{|c|}{ Characteristics } & $n=1000$ & $\%$ \\
\hline \multirow{4}{*}{ Age } & $\leq 19$ & 060 & 06.00 \\
\hline & $20-24$ & 631 & 63.10 \\
\hline & $25-29$ & 245 & 24.50 \\
\hline & $30-34$ & 064 & 06.40 \\
\hline \multirow{2}{*}{ Religion } & Hindu & 618 & 61.80 \\
\hline & Muslim & 382 & 38.20 \\
\hline \multirow{7}{*}{ Education } & Illiterate & 038 & 3.80 \\
\hline & Primary & 127 & 12.70 \\
\hline & Middle & 421 & 42.10 \\
\hline & High School & 282 & 28.20 \\
\hline & Intermediate & 108 & 10.80 \\
\hline & Graduate & 017 & 01.70 \\
\hline & Postgraduate & 007 & 00.70 \\
\hline \multirow{2}{*}{ Occupation } & Home-maker & 857 & 85.70 \\
\hline & Employed & 143 & 14.30 \\
\hline \multirow{3}{*}{$\begin{array}{l}\text { Socio- } \\
\text { Economic } \\
\text { Status* }\end{array}$} & Class 3 & 115 & 11.50 \\
\hline & Class 4 & 614 & 61.40 \\
\hline & Class 5 & 271 & 27.10 \\
\hline \multirow{2}{*}{$\begin{array}{l}\text { Type of } \\
\text { family }\end{array}$} & Nuclear & 386 & 38.60 \\
\hline & Joint & 614 & 61.40 \\
\hline \multirow{6}{*}{ Gravidity } & G1 & 533 & 53.30 \\
\hline & $\mathrm{G} 2$ & 282 & 28.20 \\
\hline & G3 & 132 & 13.20 \\
\hline & G4 & 040 & 04.00 \\
\hline & G5 & 011 & 01.10 \\
\hline & G6 & 002 & 00.20 \\
\hline \multirow{2}{*}{$\begin{array}{l}\text { Gestational } \\
\text { age }\end{array}$} & $<20$ weeks & 482 & 48.20 \\
\hline & $>20$ weeks & 518 & 51.80 \\
\hline
\end{tabular}

*Socioeconomic status by B G Prasad Classification.

Table 2: Statistical variables of correctly answered questions regarding JSSK entitlements.

\begin{tabular}{|l|l|}
\hline Variables & Value \\
\hline Mean & 6.22 \\
\hline Mode & 5 \\
\hline S.D & 3.52 \\
\hline Range & 16 \\
\hline Minimum & 0 \\
\hline Maximum & 16 \\
\hline
\end{tabular}

Table 3 showing maximum awareness regarding JSSK entitlements was noted to be for Free vaginal delivery in $869(86.90 \%)$ followed by free drugs and consumables to mother $(73.4 \%)$ and free treatment for sick infants 662 $(66.2 \%)$ and least awareness was noted for free drop back of sick infant from health facility to home (9\%) and free caesarean section $(9.6 \%)$.

Table 4: showing advancing age, increasing level of education, member of nuclear family, increasing number of conception (gravidity) and advanced gestational age are significantly associated with good awareness.
However, religion, socioeconomic status and occupation did not have any statistical significant association with the level of awareness regarding various entitlements of JSSK in antenatal women.

Table 3: Awareness regarding individual JSSK entitlements.

\begin{tabular}{|lll|}
\hline JSSK entitlements & $\mathrm{n=1000}$ & $\begin{array}{l}\% \text { of } \\
\text { patients }\end{array}$ \\
\hline Free vaginal delivery & 869 & 86.90 \\
\hline Free Caesarean section & 096 & 09.60 \\
\hline Free treatment for sick infant & 614 & 61.50 \\
\hline $\begin{array}{l}\text { Free drugs and consumables for } \\
\text { mother }\end{array}$ & 734 & 73.40 \\
\hline $\begin{array}{l}\text { Free drugs and consumables for } \\
\text { sick infants }\end{array}$ & 662 & 66.20 \\
\hline $\begin{array}{l}\text { Free diagnostics for pregnant } \\
\text { women }\end{array}$ & 611 & 61.10 \\
\hline Free diagnostics for sick infant & 578 & 57.80 \\
\hline Free diet for mother & 516 & 51.60 \\
\hline $\begin{array}{l}\text { Free provision of blood for } \\
\text { mother }\end{array}$ & 173 & 17.30 \\
\hline $\begin{array}{l}\text { Free provision of blood for sick } \\
\text { infant }\end{array}$ & 190 & 19.10 \\
\hline $\begin{array}{l}\text { Exemption from user charges for } \\
\text { mother and sick infant }\end{array}$ & 350 & 35.00 \\
\hline $\begin{array}{l}\text { Free transport for mother from } \\
\text { home to health facility }\end{array}$ & 212 & 21.20 \\
\hline $\begin{array}{l}\text { Free transport for mother } \\
\text { between health facilities }\end{array}$ & 179 & 17.90 \\
\hline $\begin{array}{l}\text { Free drop back from health } \\
\text { facility to home after delivery }\end{array}$ & 99 & 09.90 \\
\hline $\begin{array}{l}\text { Free transport for sick infant } \\
\text { from home to health facility }\end{array}$ & 146 & 14.60 \\
\hline $\begin{array}{l}\text { Free referral transport for sick } \\
\text { infant between health facilities }\end{array}$ & 137 & 13.70 \\
\hline $\begin{array}{l}\text { Free drop back of sick infant } \\
\text { from health facility to home }\end{array}$ & 090 & 09.00 \\
\hline
\end{tabular}

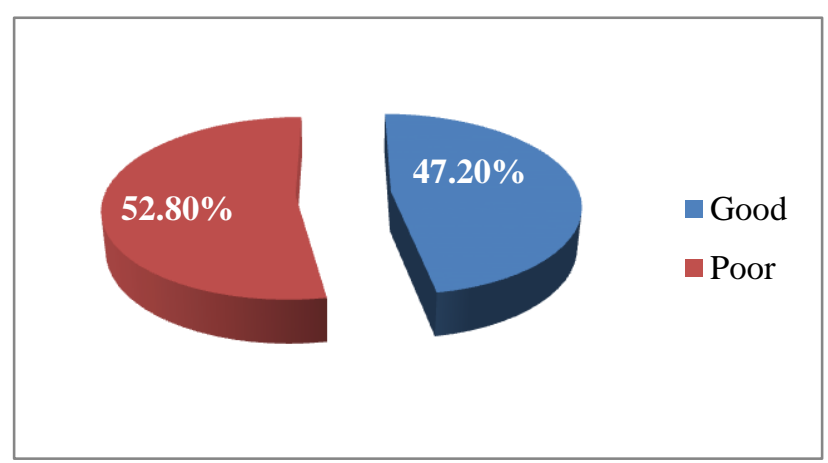

Figure 1: Awareness of JSKK.

Figure 1 showing among 1000 antenatal women, good awareness level regarding JSSK entitlements was seen in only $472(47.2 \%)$ study subjects. 
Regarding the source of information, the most common source of information was from health personnel $201(42.5 \%)$, followed by family $132(28.2 \%)$ and friends
75 (15.8\%). None of the women reported that Radio, TV, Newspaper had contributed as a source of information (Table 5).

Table 4: Association of socio-demographic factors with awareness level.

\begin{tabular}{|c|c|c|c|c|c|}
\hline Socio-demograp & factors & $\begin{array}{l}\text { Poor Awareness } \\
\text { n }(\%)\end{array}$ & $\begin{array}{l}\text { Good awareness } \\
\text { n }(\%)\end{array}$ & Total n (\%) & $P$ value \\
\hline \multirow{4}{*}{ Age } & $<20$ & $38(63.3)$ & $22(36.7)$ & $60(100)$ & \multirow{4}{*}{0.001} \\
\hline & $20-24$ & $352(55.8)$ & $279(44.2)$ & $631(100)$ & \\
\hline & $25-29$ & $103(42)$ & $142(58)$ & $245(100)$ & \\
\hline & $30-34$ & $30(52.3)$ & $34(47.7)$ & $64(100)$ & \\
\hline \multirow{2}{*}{ Religion } & Hindu & $328(53.1)$ & $290(46.9)$ & $618(100)$ & \multirow{2}{*}{0.533} \\
\hline & Muslim & $195(51)$ & $187(49)$ & $382(100)$ & \\
\hline \multirow{7}{*}{ Education } & Illiterate & $29(76.3)$ & $9(23.7)$ & $38(100)$ & \multirow{7}{*}{0.000} \\
\hline & Primary & 90(70.9) & $37(29.1)$ & $127(100)$ & \\
\hline & Middle & $279(66.3)$ & $142(33.7)$ & $421(100)$ & \\
\hline & High School & $76(27)$ & 206(73) & $282(100)$ & \\
\hline & Intermediate & $42(38.9)$ & $66(61.1)$ & $108(100)$ & \\
\hline & Graduate & $4(23.5)$ & $13(76.5)$ & $17(100)$ & \\
\hline & Postgraduate & $3(42.9)$ & $4(57.1)$ & $7(100)$ & \\
\hline \multirow{2}{*}{ Occupation } & Homemaker & $441(51.5)$ & $416(48.5)$ & $857(100)$ & \multirow{2}{*}{0.192} \\
\hline & Employer & $82(57.3)$ & $61(42.7)$ & $143(100)$ & \\
\hline \multirow{3}{*}{$\begin{array}{l}\text { Socioeconomic } \\
\text { Status }\end{array}$} & Class 3 & $68(59.1)$ & $47(40.9)$ & $115(100)$ & \multirow{3}{*}{0.158} \\
\hline & Class 4 & $308(50.2)$ & $306(49.8)$ & $614(100)$ & \\
\hline & Class 5 & $147(54.2)$ & $124(45.8)$ & $271(100)$ & \\
\hline \multirow{2}{*}{ Family } & Nuclear & $168(43.5)$ & $218(56.5)$ & $386(100)$ & \multirow{2}{*}{0.000} \\
\hline & Joint & $355(57.8)$ & $259(42.2)$ & $614(100)$ & \\
\hline \multirow{6}{*}{ Gravidity } & G1 & $408(76.5)$ & $125(23.5)$ & $533(100)$ & \multirow{6}{*}{0.000} \\
\hline & G2 & $68(24.1)$ & 214(75.9) & $282(100)$ & \\
\hline & G3 & $36(27.3)$ & $96(72.7)$ & $132(100)$ & \\
\hline & G4 & $10(25)$ & $30(75)$ & $40(100)$ & \\
\hline & G5 & $1(9.1)$ & $10(90.9)$ & $11(100)$ & \\
\hline & G6 & $0(0)$ & $2(100)$ & $2(100)$ & \\
\hline \multirow{2}{*}{ Gestational Age } & $<20$ weeks & $380(78.8)$ & 102(21.2) & 482(100) & \multirow{2}{*}{0.000} \\
\hline & $>20$ weeks & 143(27.6) & $375(72.4)$ & $518(100)$ & \\
\hline
\end{tabular}

Table 5: Source of information regarding JSSK entitlements in women with good awareness.

\begin{tabular}{|c|c|c|c|c|c|c|c|}
\hline Scheme & \multicolumn{7}{|c|}{ Table of source of information } \\
\hline $\begin{array}{l}\text { JSSK source of } \\
\text { info of subjects } \\
\text { having good } \\
\text { awareness }\end{array}$ & $\begin{array}{l}\text { Health care } \\
\text { personnel }\end{array}$ & TV & Radio & Newspaper & Family & Friend & $\begin{array}{l}\text { Asha } \\
\text { worker }\end{array}$ \\
\hline $472(100 \%)$ & $201(42.5 \%)$ & 0 & 0 & 0 & $132(28.2 \%)$ & $75(15.8 \%)$ & $64(13.5 \%)$ \\
\hline
\end{tabular}

\section{DISCUSSION}

Developing countries today still face high maternal and infant mortality rates. Maternal and child mortality is expected to be reduced by promoting institutional deliveries. To address this issue, the Government of India launched JSSK in 2011 to provide free-of-cost care for delivery including transport, drugs, investigations, diet and blood. ${ }^{3}$ It is complete cashless scheme to give free services to all pregnant woman and sick neonates irrespective of their economic condition.Increasing trend has been seen in India in Percentage of Institutional Deliveries $70.625 \%$ in $2008-09$ and $82.864 \%$ in 2012 $13 .^{5}$ However still about $17 \%$ of pregnant women are 
delivering at home and those deliver at institution are unwilling to stay for 48 hours, hampering the provision of essential services both to mother and neonate which are critical for identification and management of complications during first 48 hours of delivery. Though the government intention was good, utilization of scheme remained poor. While going in depth of non-utilization of service to the fullest extent, we found ignorance and less information among pregnant women regarding JSSK scheme. There were very few studies stating level of awareness regarding JSSK entitlements and its association with socio-demographic factors. This hospital based cross sectional study was conducted to find out the level of awareness in pregnant women coming to attend antenatal clinic who are the immediate beneficiaries of the scheme.

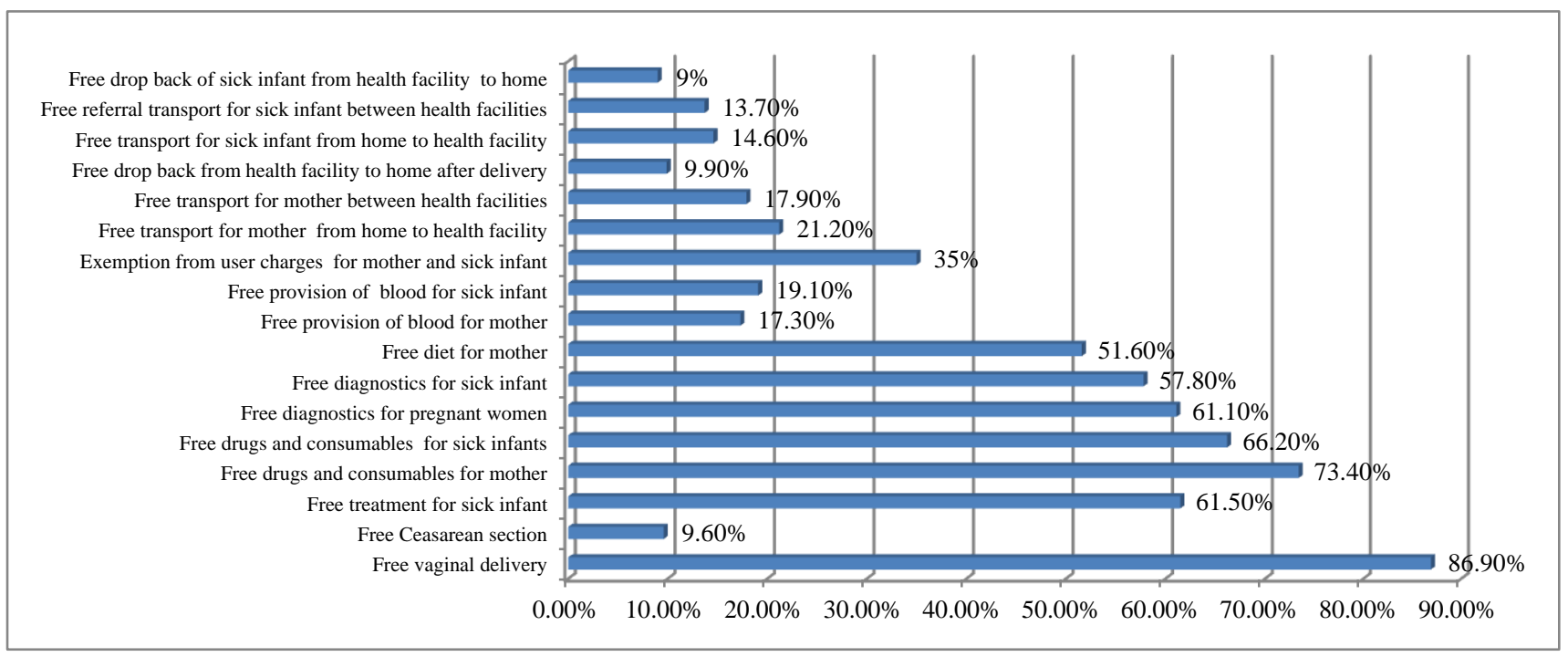

Figure 2: Awareness regarding individual JSSK entitlements in study subjects.

In the present study, good awareness was observed among $47.2 \%$ pregnant women whereas in a study conducted among pregnant women from West Bengal reported good awareness in $31.25 \% .^{5}$ In a study conducted at Karnataka among pregnant women, not a single subject was aware about JSSK entitlements and they emphasised the reason could be that the study was conducted in a private rural hospital where most of the government maternity benefit schemes were not available. ${ }^{6}$ In the present study, $86.9 \%$ were aware of free normal vaginal delivery and only $9.6 \%$ were aware of free caesarean section whereas in a West Bengal study only $18.75 \%$ of the pregnant mothers were aware of free normal vaginal delivery and none knew about the provision of free caesarean section. ${ }^{5}$ However, in an Assam study which was conducted on mothers who had delivered within the past one year, $88.1 \%$ were aware of free delivery. ${ }^{7}$

Around $61.5 \%$ of pregnant women of our study were aware about free treatment for sick infant whereas $10.42 \%$ and $26.1 \%$ of subjects were aware of free treatment of sick infant in West Bengal and Assam study respectively. ${ }^{5,7}$

Awareness regarding free drugs and consumables for pregnant women $(73.4 \%)$ and sick infants $(66.2 \%)$ was comparatively higher in present study than the awareness in West Bengal pregnant women which was $18.75 \%$ and
$10.42 \%$ respectively, whereas in the Assam study awareness on free drugs \& consumables was $85 \% .^{5,7}$

In the present study $61.1 \%$ and $57.8 \%$ pregnant women were aware about free diagnostics for pregnant women \& sick infant respectively. Whereas in West Bengal study, $29.17 \%$ and $6.25 \%$ were aware of free diagnostics for pregnant women and sick infant respectively. ${ }^{5}$ In the Assam study awareness about free diagnostics was $77 \% .^{7}$

Awareness level for free diet (51.6\%) in the present study was comparable with that of West Bengal study $(58.33 \%)$, whereas awareness of free diet for mothers was $80.1 \%$ in the Assam study. ${ }^{5,7}$

In the present study free provision of blood for mother \& sick infant was $17.3 \%$ and $19 \%$ respectively whereas none of the respondents was aware of free provision of blood for mother and sick infant in the West Bengal study. ${ }^{5}$ According to Assam study $17.8 \%$ mothers were aware of free provision of blood for mother and sick infant. ${ }^{7}$

In the present study $35 \%$ pregnant women were aware about no user charges whereas $14.58 \%$ pregnant women knew about no user charges in West Bengal study. ${ }^{5}$ However as per Assam study as high as $85 \%$ respondents were aware about no user charges. ${ }^{7}$ 
Awareness on free transport to pregnant women from home to health facility, between health facilities and drop back from health facility to home was $21.2 \%, 17.9 \%$ and $9.9 \%$ respectively, whereas it was comparatively higher in West Bengal study that is $35.42 \%, 18.75 \%$ and $35.42 \%$ respectively. ${ }^{5}$ In the present study, awareness about free transport facility for sick infant from home to health facility, between health facilities and drop back from health facility to home is $14.6 \%, 13.7 \%$ and $9 \%$ respectively whereas it was $16.6 \%, 12.5 \%$ and $16.6 \%$ respectively in West Bengal study. ${ }^{5}$ In the Assam study awareness on free transport from home to health facility, free referral transport and free drop back from health facility to home was much higher that is $82.7 \%, 40.3 \%$ and $72.4 \%$ respectively. ${ }^{7}$ A study conducted at Solapur and study conducted Wardha from Maharashtra state reported that $45.6 \%$ and $44.17 \%$ participants were aware about free transport service available under JSSK respectively. ${ }^{8,9}$

The present study and West Bengal study were conducted among pregnant women, whereas the Assam study was conducted among mothers who had delivered within the past one year. This may be one of the reasons for wide differences regarding awareness about JSSK entitlements in different studies.

The present study noted that advancing maternal age, increasing level of education, member of nuclear family increasing number of conception (gravidity) and advanced gestational age were significantly associated with good awareness. However, religion, socioeconomic status and occupation did not have any statistical significant association with the level of awareness regarding various entitlements of JSSK in antenatal women. In a study from West Bengal reported religion, caste, socio-economic status of mother, number of antenatal visits had no significant association with the awareness level regarding JSSK. However, parity of mother had statistically significant relationship with awareness level among the pregnant mothers about JSSK $(\mathrm{p}<0.05)$. Mothers having previous history of childbirth are more aware of the various entitlements of JSSK in comparison to those who were pregnant for the first time.(5)

Our study showed that the source of information is mainly from health personnel 201 (42.5\%) (Health workers, Health professionals), followed by family 132 (28.2\%), friends $75(15.8 \%)$ and ASHA workers 64 (13.5\%). Radio, TV, Newspaper has not contributed to any source of information. Similar observation is noted by a study conducted at Karnataka on awareness about different maternity benefits. ${ }^{6}$ A cross sectional study was conducted by Mohapatra et al on assessment of the functioning and impact of Janani Suraksha Yojana in Orissa, revealed that health worker female and accredited social health activists were playing key roles in generating awareness regarding Janani Suraksha Yojana. ${ }^{10}$
Overall awareness level on JSSK entitlements is poor. There is still a long way to achieve good awareness in large number of beneficiaries to bring out proper utilization of JSSK services to its fullest extent.

\section{CONCLUSION}

Awareness level of JSSK entitlements in the pregnant women in our study is low. Maximum awareness was noticed for the provision of free vaginal delivery whereas awareness for provisions like free caesarean section, free drop back facility to home, free provision of blood is very low. Further efforts are needed to increase the overall awareness of various entitlements of JSSK among pregnant women to increase the utilization of the benefits of the scheme and thus indirectly helping in reducing MMR and IMR.

This study was not community based and along with awareness, utilization should have been assessed.

Funding: No funding sources Conflict of interest: None declared

Ethical approval: The study was approved by the Institutional Ethics Committee

\section{REFERENCES}

1. Park K. Preventive and Social Medicine. Chapter 10. Preventive Medicine in Obstetrics, Paediatrics and Geriatrics. Edition 20. Jabalpur. 2009. pp. 447-525

2. Maternal Mortality Ratio Bulletin 2011-2013. Sample Registration System. Available from: www.censusindia.gov.in.

3. Ministry of Health and Family Welfare. Guidelines for Janani Shishu Suraksha Karyakram (JSSK). National Rural Health Mission ,Maternal Health Division, Government of India, Nirman bhavan, New Delhi, June 2011.

4. Mahajan BK. Methods in Biostatistics for Medical Students and Research Workers. Chapter 6 . Sampling. Edition 8. pp. 113-127.

5. Trends in Child Delivery at Health Facilities (Institutional Delivery) across India from 2008-09 to 2012-13, Community data.gov.in.

6. Chatterjee S, Das D. Awareness about Janani Shishu Suraksha Karyakram (JSSK) among pregnant mothers - a community based study in rural area of West Bengal, India. IOSR Journal of Dental and Medical Sciences. 2015;14(9):01-57.

7. Johnson AR, Rock B, Catherin N. Awareness of Government Maternity Benefit Schemes among women attending antenatal clinic in a rural hospital in Karnataka, India ,International journal of current research and academic review. 2015;3(1):137-43.

8. Barua K. Awareness and utilisation of Janani Shishu Suraksha Karyakram (JSSK) in rural areas of Kamrup District, Assam. (Unpublished).

9. Mangulikar SK, Shinde P. A cross sectional study to assess the Knowledge and Practice about free 
transport service available under JSSK, among the Post-natal Mothers at a tertiary care Hospital in Maharashtra. IJIMS. 2015;2(11):4-8.

10. Goyal RC, Singh P. Assessment of implementation status of Janani-shishu suraksha karykram (JSSK) for free referral transport services At selected public health facilities in Wardha district, of central India. Int J Cur Res Rev. 2014;6(16).

11. Mohapatra B, Datta U. An assessment of the functioning and impact of JSY in Orissa. Publ J Arch. 2008;31(2):235-9.

Cite this article as: Deshpande $\mathrm{S}$, Gadappa $\mathrm{S}$, Pagare S, Dhaduti R, Andurkar S. Awareness regarding Janani Shishu Suraksha Karyakram among pregnant women of Marathwada, Maharashtra, India. Int J Reprod Contracept Obstet Gynecol 2016;5:1985-91. 